\title{
LA RESISTENCIA DE LOS TARAPAQUEÑOS AL MONOPOLIO SALITRERO PERUANO DURANTE EL GOBIERNO DE MANUEL PARDO, DESDE EL ESTANCO A LA EXPROPIACIÓN (1872-1876)
}

\author{
THE RESISTENCE OF "TARAPAQUEÑOS" TO THE PERUVIAN NITRATE \\ MONOPOLY DURING MANUEL PARDO GOVERNMENT, FROM "ESTANCO" \\ TO EXPROPRIATION (1872-1876)
}

Sergio González Miranda ${ }^{1}$

\begin{abstract}
Este artículo analiza el desarrollo de la política salitrera durante el Gobierno de Manuel Pardo (1872-1876), desde el estanco hasta la expropiación de la industria del nitrato, destacando la resistencia de los salitreros tarapaqueños. Esta resistencia es analizada como un movimiento social en defensa de intereses regionales respecto de intereses de grupos capitalistas limeños, que poseían el poder económico, por medio de la Banca peruana, y el poder político, a través del Gobierno central.

Se plantea que dicha política salitrera, que consideraba el monopolio del nitrato como su principal herramienta, fue una pieza central de un proyecto modernizador, cuyo objetivo fue controlar todo el territorio salitrero peruano (y también el territorio salitrero boliviano de $\mathrm{El} \mathrm{Toco}$ ). Este proyecto de modernización, iniciado e ideado durante el Gobierno de Manuel Pardo, ocultaba los intereses de los banqueros limeños por controlar la economía salitrera una vez perdida la economía del guano en manos de la Casa Dreyfus. Bajo el argumento del interés nacional se expropió al capital extranjero, especialmente chileno e inglés, como así también al capital regional tarapaqueño, que entonces era mayoritario.

Palabras claves: Salitre, Tarapacá, monopolio, modernización y política salitrera, resistencia regional.
\end{abstract}

This article analyzes the development of the saltpeter politics during Manuel Pardo's administration (1872-1876), from the "Estanco" to the expropriation of the nitrate industry, emphasizing the resistance of the saltpeter miners in Tarapacá. This resistance is analyzed as a social movement to defend regional interests of groups from Lima, who exercised economic power through Peruvian banks and political power through the central government.

In the realm of saltpeter politics, nitrate monopoly was considered to be a primary tool in the process of modernization, the objective of which was to control the whole Peruvian (as well as the Bolivian) saltpeter territory. This modernization project, initiated and conceived during Manuel Pardo's government, hid the interests of the Lima bankers to control the saltpeter economy once the guano economy was lost in the hands of the Dreyfus firm. Under the guise of national interest, foreign saltpeter capital mine was expropriated, particularly Chilean and English, as well as capital from Tarapacá that was a majority.

Key words: Saltpeter industry, Tarapacá, nitrate, monopoly, modernization and politics, regional resistance.

La Historia del Salitre en Tarapacá tiene varios capítulos, algunos más estudiados que otros, como el periodo de expansión (1880-1920) respecto de los periodos de inicio (1830-1870) y término del ciclo del nitrato (1930-1978). Existen, además, subperiodos que han concentrado atención especial por su importancia, uno de ellos es aquel cuando se implementó la política de monopolio del salitre, entre 1872 y 1876.

Esta política salitrera fue diseñada durante el Gobierno de Manuel Pardo, supuestamente, dentro de un proyecto político de modernización del Estado peruano. Sus principales instrumentos fueron, primero, la creación de un estanco salitrero y, después, la promulgación de una Ley de Expropiación de la industria salitrera existente hasta entonces. $\mathrm{La}$ explotación del salitre peruano estaba exclusivamente ubicada en la provincia de Tarapacá.

La justificación que se esgrimió para llevar adelante esta política de expropiación de la industria salitrera fue, entre otros argumentos, una importante presencia de capitales ingleses y chilenos que, por ser extranjeros, supuestamente, obstaculizarían el desarrollo del proyecto de modernización que había ideado el presidente Manuel Pardo y su círculo civilista. Se asoció este proyecto con la idea

$\overline{1}$ Instituto de Estudios Internacionales, Universidad Arturo Prat. Dirección Postal: Casilla 121, Iquique, Chile. pampino50@ gmail.com 
de Nación o de Patria ${ }^{1}$. Esa justificación continúa siendo sostenida en la historiografía peruana actual, incluso la relacionan con la Guerra del Pacífico, en el sentido que los capitales ingleses y chilenos habrían reaccionado ante esa política salitrera creando una alianza. Wilfredo Kapsoli señala que la política nacionalista peruana, en desmedro del capital privado y extranjero, fue el factor desencadenante de la Guerra del Pacífico. Responsabiliza a Inglaterra de provocar directamente el conflicto, con el fin de apropiarse de la riqueza peruana (De Lavalle 1979:30). En esa misma dirección tenemos a Alejandro Reyes Flores (1979) y a Enrique Amayo (1988), entre otros.

Llama la atención que se continúe sosteniendo esta hipótesis, a pesar de la estudiada relación entre el Gobierno del Perú con compañías inglesas, como la Casa Gibbs, que fueron notoriamente favorecidas con un sobreprecio en la compra de sus propiedades salitreras (Ravest 2008a), debido a las relaciones privilegiadas que tenía con el Gobierno peruano desde su participación en la economía del guano desde 1840 en adelante (Mathew 2009). Fue Gran Bretaña, además, el país más importante en el comercio exterior peruano en la primera mitad del siglo XIX (Flores Galindo 1980).

La alianza entre el capital privado peruano y el capital británico se expresó en la economía del guano, que endeudó al Estado de ese país tanto interna como externamente; fue por ello que el presidente José Balta y su Ministro de Hacienda, Nicolás de Piérola, intentaron quebrar esa alianza buscando empréstitos externos, específicamente con la Casa Dreyfus y Hnos., de origen judío-francés, con la que firmó un contrato el 17 de agosto de 1869. El historiador peruano Rolando Pereda nos dice que "la reacción al contrato, a cargo de un grupo de capitalistas nacionales denominados "los hijos del país", fue inmediata (Pereda 1982:45)". Este autor señala que dieron a conocer su posición a través de un documento denominando "Demanda de los Nacionales". Fue, efectivamente, una reacción en contra del capital extranjero, pero no se trataba del capital inglés y menos del chileno.

El vínculo de Manuel Pardo en la década de 1860 y los comerciantes del guano era conocido en Perú, "habían desarrollado una campaña en $L a$ Revista de Lima destinada a modificar la política económica seguida por los caudillos gobernantes" (Cotler 2006:113), dicha campaña permitió la constitución del Partido Civil, que llevaría a Pardo al poder $\mathrm{y}$, por su intermedio, desarrollar un proyecto político liberal pragmático basado en un "desarrollo hacia fuera" (Cotler 2006:113).

Pardo alcanzó un liderazgo que lo construyó con una estrategia desarrollada a partir de las elecciones de 1871. Estas elecciones fueron, como lo demuestra Ulrich Mücke (2004:163) “el punto de partida de una breve historia de éxito en las elecciones peruanas". Sin ser democráticas se ampliaron a otros sectores más allá de la oligarquía dominante en ese país, generándose una importante competencia desconocida hasta entonces, recurriendo Pardo a una red de organizaciones, a movilizaciones sociales e incluso enfrentamientos. Mücke (2004:150) señala que "antes de la Guerra con Chile ningún otro (candidato) logró establecer una red de comunicaciones tan extensa, y en ese mismo periodo probablemente ningún candidato fue respaldado por tantos clubes electorales". Cabe destacar que el éxito le fue esquivo a Pardo precisamente en las regiones del sur de Perú; había ganado con el $69 \%$ de los votos de los delegados, pero "el número de clubes electorales y sus cartas mostraban que su candidatura estaba mejor establecida en el norte del país, y era más débil en el sur" (Mücke 2004:158). A pesar de esta mayor apertura electoral, ello no significaba un cambio en la base de apoyo de Pardo, que era básicamente limeña. Respecto de la fundación de la Sociedad Independencia Electoral (SIE), que será la base del Partido Civil ${ }^{2}$, sus miembros, nos dice Mücke (1997:88), eran "hacendados, banqueros, comerciantes, periodistas, oficiales de la marina y ejército, y artesanos exitosos", es decir, además de la oligarquía tradicional se sumaba una plutocracia emergente. Habría tenido la SIE, según Mc Evoy (1997), un "ciudadano imaginado", que incluía sectores populares, cuya "vanguardia" estaría en los sectores medios. El proyecto político de Pardo generaría la fuerza centrípeta necesaria para unir a todos esos grupos, allí residía su liderazgo.

Con la llegada de Manuel Pardo al Gobierno en 1872, este grupo de capitalistas nacionales vio en el salitre, que ese año superó al guano en las exportaciones peruanas (Bonilla 1980:43), la posibilidad de volver a recibir los beneficios que años antes les otorgó el monopolio del guano (Mathew 2009). Había, entonces, que volver a pensar en un nuevo monopolio: el salitre. 


\section{Antecedentes: Tarapacá y el Salitre}

Tarapacá a inicios del siglo XIX era la más austral provincia del Perú. Ya había terminado la época de la plata y no estaba plenamente integrada a la economía del guano, a pesar que poseía importantes covaderas en Pabellón de Pica y Huanillos, incluso la isla frente al puerto de Iquique, llamada entonces de Cuadros, era también guanera. No era una provincia que concentrara las miradas de los intereses capitalistas limeños, fueran políticos o empresariales. Sólo cuando hacia 1828 el gobierno del Perú autorizó la exportación de salitre por Iquique, este puerto inició su lento desarrollo (Donoso 2003:16).

No había grandes firmas inglesas ni chilenas operando en Tarapacá, eran mineros llenos de audacia y dispuestos al riesgo, verdaderos visionarios como Sebastián de Ugarrisa y Matías de la Fuente, quienes vieron en el salitre una alternativa para la fabricación de pólvora. Algunos habían trabajado en la minería de la plata, como George Smith. Otros, como Pedro Gamboni, llegaron directamente a levantar la industria del nitrato desde Chile. De ese modo, se fue desarrollando la industria del salitre, producto de un esfuerzo privado de empresarios locales y extranjeros. La Banca limeña y el puerto del Callao estaban ajenos a la economía del nitrato, no así la Banca chilena y el puerto de Valparaíso, que facilitaron el capital necesario y la plataforma importadora y exportadora.

Y el esfuerzo de tarapaqueños y extranjeros no sería en vano, al iniciarse la década de 1870 el salitre es protagonista en la economía peruana, que estaba en crisis. Sin embargo, el mismo grupo que llevó al poder a Manuel Pardo el 24 de abril de 1872, había tenido la oportunidad de transformar al Perú en una nación moderna, gracias al venero de riqueza que había generado la economía del guano. Heraclio Bonilla, se pregunta:

Pero, incluso en su situación de socios menores, el acceso a la consignación del guano a la Gran Bretaña les permitió la acumulación de una colosal fortuna. Aquí existió pues la posibilidad histórica de financiar el desarrollo económico del Perú. Pero como este desarrollo no se produjo, es necesario preguntarse qué fue lo que impidió la transformación de la acumulación primitiva del capital-dinero en acumulación primitiva del capital industrial. La respuesta es necesariamente tentativa, pues no se dispone hasta ahora de las evidencias suficientes que permitan un examen adecuado de esta cuestión. Los indicios establecen, sin embargo, que estos capitales no sirvieron para renovar integralmente la estructura del país (Bonilla 1974:39).

Porque eran fundamentalmente banqueros y no industriales. El propio Bonilla nos recuerda que entre 1862 y 1869 se crearon los cinco primeros bancos del Perú: Banco de la Providencia (1862), Banco del Perú (1863), Banco de Londres, México y Sudamérica (1863), Banco de Crédito Hipotecario (1866) y Banco de Lima (1869). Este hecho es muy significativo "hasta 1862 todas las operaciones de crédito y de descuento eran realizadas exclusivamente por las casas comerciales o por las compañías consignatarias" (Bonilla 1974:40). Alejandro Reyes Flores plantea que los bancos La Providencia, Nacional del Perú, Lima y aun Bancos Hipotecarios, "se convirtieron en acreedores del propio gobierno, mediante préstamos a cuenta de la venta del guano que por Ley era propietaria del Estado" (Reyes Flores 1979:103). Agrega este autor:

Para la década del 60, cuando los nacionales usufructuaron de este lucrativo negocio, el porcentaje que correspondía al guano en relación con el total de nuestras exportaciones, fluctuó entre un 45\% a 60\%. Había dinero a raudales, pero se dilapidó (Reyes Flores 1979:103).

No era de extrañar que los mismos grupos que accedieron a la renta del guano quisieran ser también los beneficiarios de la renta del salitre que hasta entonces (1872) no había estado en el horizonte de sus intereses. De ese modo aparece Tarapacá y su riqueza salitrera en el proyecto político de Manuel Pardo ${ }^{3}$.

El proyecto modernizador de Pardo era frágil por "la prescindencia del camino industrializador, que coloca al proyecto con ciertos reparos dentro de aquello que se denomina "modernización tradicional" (Mc Evoy 1994:305), y también lo era en su aspecto más novedoso: su carácter urbano, especialmente porque se pensaba digitar desde Lima una economía minera e industrial ubicada en el extremo sur del país e, incluso, más allá de las fronteras del Perú en la rica región boliviana de El Toco (González 2006; Ravest 2008a). 
Pardo intentó no repetir lo que le había sucedido al Perú con el guano; de ese periodo nos dice William M. Mathew: "toda la historia financiera del Perú en nuestro periodo de estudio (1840-1862), como lo han documentado Moqueen, Bonilla y otros, muestra un gran desenfreno, ausencia de planificación previa y una aparente disposición descuidada para hipotecar el futuro" (Mathew 2009:297). Era, sin embargo, muy difícil un cambio cultural y económico durante el período salitrero, si Pardo lo pensaba hacer empinado en los hombros del mismo círculo de banqueros de la fracasada economía del guano. Probablemente, los industriales salitreros de Tarapacá, peruanos y extranjeros, desconfiaron de dicho círculo y resistieron para evitar que sus esfuerzos de medio siglo terminaran en las mismas manos de quienes habían endeudado el fisco del Perú, aunque ahora estuvieran ocultos detrás del discurso de un nuevo Estado y de un proyecto nacional, bajo el liderazgo de Manuel Pardo.

El nitrato se develaba en 1872 ante los ojos de los capitalistas limeños vinculados al civilismo. Sin embargo, los tarapaqueños llevaban más de medio siglo trabajando esta minería, lo que les significó muchos sacrificios al enfrentar el desierto, donde no siempre obtuvieron beneficios. Los ingenieros alemanes Semper y Michels, nos dicen que "ya por los años 1870 a 1872 se habían levantado 18 oficinas con un poder productor anual de 3.200 .000 quintales (de salitre). En los años siguientes de 1872 a 1878 se levantaron 55 oficinas nuevas con capacidad productora de 13.698.000 quintales" (Semper y Michels 1908:133).

La historiadora Carmen Mc Evoy nos habla que "el nuevo ciclo exportador salitrero abría inmensas posibilidades de desarrollo económico para las elites económicas nativas. Cabe recordar como, dentro del contexto anterior, la Banca limeña, aliada estratégica del Partido Civil, ocuparía un lugar de honor en el reparto del nuevo botín fiscal" (Mc Evoy 1997:202). Donde, por cierto, el estanco era el principal instrumento de recaudación de ese nuevo botín fiscal, cuando los ingresos por el guano estaban yendo directamente a las manos del principal acreedor del Perú: la Casa Dreyfus.

El más conocido historiador del salitre, Óscar Bermúdez, comparte la política económica de Pardo, pues nos dice que "los impugnadores de la política salitrera del gobierno de Pardo han sostenido en sus escritos, todavía treinta años después de la Guerra del Pacífico, que la ley del estanco se impuso contra los intereses de la industria y la voluntad de los salitreros. Sin embargo, documentos de la prefectura de Tarapacá en los archivos peruanos (AGN) apuntan en la dirección contraria a lo manifestado por Bermúdez. En el Archivo General de la Nación (Perú), ubicado en Lima, hemos encontrado en el Fondo de Hacienda, Sección Expedientes Oficiales, Prefectura de Tarapacá, varios documentos relativos al tema del Estanco salitrero, como los fechados: 31/7/1873, volumen O.L. 514-1914-2056, 10 fojas; 29/8/1873, volumen O.L. 514-1914-2056, 5 fojas; 9/9/1873, volumen O.L. 514-1914-2056, 10 fojas. Donde el primero informa sobre las dificultades que conlleva el estanco, el segundo una solicitud de los salitreros para que se revisen las disposiciones del decreto reglamentario del estanco y, el tercero, claramente expresa el descontento de los industriales ante el estanco salitrero. El primer pensamiento de don Manuel Pardo, al hacerse cargo del gobierno, no fue el de monopolizar por el Fisco las ventas del salitre sino el de aplicar un nuevo tipo de impuesto, más flexible que los anteriores" (Bermúdez 1963:325). Este autor no es el único especialista chileno que observó con interés la política salitrera peruana, y en particular el estanco, también lo hizo Francisco Valdés Vergara, quien fuera además Jefe Político de Tarapacá y uno de los economistas más agudos del Chile de fines del siglo XIX y comienzos del XX. Valdés Vergara señalaba:

Desde 1880 todos los actos del Gobierno chileno, inspirados por la doctrina del libre cambio y de la incapacidad industrial del Estado, se encaminaron en el sentido de destruir el estanco. Hoy se ve con claridad que eso fue un error, pues el régimen fiscal peruano era bien concebido, armonizaba los intereses nacionales con la libertad de trabajo y no anulaba la iniciativa individual en esa industria (Valdés 1913:360).

El historiador peruano Jorge Basadre llegó incluso a afirmar que Valdés Vergara "conecta las ideas de Pardo con las de Balmaceda" (Basadre 1969:61).

Valdés Vergara nos dice que la explotación de las salitreras, en esa época, "quedó entregada a industriales libres que suscribían con el Estado contratos de elaboración por cantidades y en condiciones fijas, de suerte que éste era dueño de las salitreras, sin ser industrial ni mezclarse en los 
negocios y los trabajos de los que elaboraban salitre" (Valdés 1913:360). Los salitreros de Tarapacá no lo sintieron así, comprendieron que se venía el control estatal similar a lo acontecido con el guano, donde la riqueza tuvo un destino conocido en los contratos realizados por el entonces Ministro de Hacienda del Gobierno de Balta, Nicolás de Piérola. Es decir, las salitreras de Tarapacá no terminarían en manos de "industriales libres", sino aquellos del círculo cercano al presidente Pardo. La ley de nacionalización de la industria salitrera era, en definitiva, una transferencia de capitales desde la provincia hacia el centro nacional.

Por su parte, Bermúdez nos dice además que "la industria de Tarapacá en momentos en que se pedía de ella una contribución extraordinaria al bien de la nación, algo más del $40 \%$ de la producción hecha en oficinas de máquina estaba controlada por capitales extranjeros: chileno, inglés, alemán y francés. Dentro de este sector extranjero, el aporte chileno era casi tan importante como el formado por el grupo europeo" (Bermúdez 1963:329). Sin embargo, no destaca que el $60 \%$ restante era de empresarios peruanos, la mayoría tarapaqueños, quienes debieron, aunque no estuvieran de acuerdo, "hacer esa contribución a la Nación", que al final del periodo significó la pérdida de sus industrias.

También un intelectual y político peruano de cultura general, José Arnaldo Márquez, apoyó la política del presidente Pardo. Este ensayista escribió anónimamente en Chile, en el periódico La Libertad Electoral, en 1888, un documento titulado "La orgía financiera del Perú. El guano y el salitre”, donde critica duramente al Gobierno de José Balta y especialmente a su Ministro de Hacienda Nicolás de Piérola, por haber dilapidado los recursos públicos y haber entregado en 1872 al Gobierno de Manuel Pardo una economía en crisis y a una Nación sin crédito. Justifica la política de expropiación de este mandatario porque habían proliferado las salitreras en Tarapacá, creando una "competencia encarnizada", entonces, afirma este autor, "el Gobierno quiso poner término a una situación desastrosa para todos, procurando fijar una limitación a las ventas de salitre: limitación que permitiera a la industria obtener una ganancia suficiente en proporción a los capitales invertidos, y que al mismo tiempo evitase en cuanto fuera posible la depreciación del guano en los mercados..." (Márquez 1888:113). Resulta llamativa esta interpretación donde el estanco resultaría beneficioso para los propios industriales, especialmente para los pequeños y medianos que tenían menos capacidad de competir, es decir, precisamente los tarapaqueños. Es, sin embargo, mucho más cercana a la realidad la segunda parte de su afirmación relativa a la protección del precio del guano en el mercado internacional.

\section{Desde el Estanco Salitrero a la Ley de Expropiación}

Lo que deseaban el presidente Pardo y su ministro Elguera era no sólo acceder a la riqueza salitrera, sino mover el principal eje comercial del nitrato, incluyendo por cierto la placa bancaria, desde Valparaíso hacia el Callao. Fueron el puerto chileno y sus bancos los que habían apoyado a los salitreros mientras el Gobierno peruano se concentraba en el guano y olvidaba a la lejana Tarapacá. Por esta razón el nitrato de Tarapacá fue conocido en el mundo como nitrato de Chile.

Nada, sin embargo, detendría a Manuel Pardo en su afán por reemplazar al guano por el salitre como la piedra de toque para impulsar su proyecto político nacional o, como lo creía Guillermo Billinghurst, entregarle a una elite financiera limeña, que este autor denomina "el círculo" y que, según Carmen Mc Evoy, se autodenominaban "los decentes" (Mc Evoy 1997:202), el poder real de la economía peruana. Sin embargo, no serían sólo peruanos los que formarían parte de este círculo de poder, la firma inglesa Gibbs, que se benefició del monopolio del guano, parecía hacerlo también del monopolio del nitrato.

Para entender el proyecto político de Pardo y su relación a la economía salitrera, es importante analizar las medidas que tomó durante su gobierno. Los diferentes decretos y leyes que el Gobierno emitió en el breve de tiempo entre 1873 y $1876^{4}$. Antes, debemos reconocer que la primera medida que intentó controlar la libertad de acción de los salitreros en Tarapacá fue un decreto del 30 de noviembre de 1868, durante el Gobierno de José Balta, que suspendía la adjudicación de estacas salitreras, que hasta entonces se pedían sin ningún reglamento.

Estanco salitrero: 18 de enero de 1873. Establecía que el Estado pagara al contado 2 soles 40 centavos por cada quintal de salitre cuya ley no baje de un $95 \%$ puesto al costado de la lancha. También consideraba la prohibición en toda la República del Perú la adjudicación de los terrenos salitreros, la 
exportación del caliche, la exportación del salitre que no haya sido comprado por el Estado.

Organización del estanco: 12 de julio de 1873. Este decreto establecía el pago por quintal de salitre de $95 \%$ de ley al costado de lancha en los puertos de Tarapacá, 2 soles 40 centavos, monto que bajaba en forma proporcional en la medida que la ley del salitre era menor. Fijaba la cantidad de salitre que el estanco compraría ese año: 4.500.000 quintales. Una Comisión habría de definir la cantidad (cuotas) que debería comprarle a cada productor. Si dicha Comisión no se constituía (como efectivamente aconteció) consideraba este decreto que el Prefecto de Tarapacá definiera dichas cuotas. Los productores podían exportar nitrato sin entregarlo al estanco, en cuyo caso le pagaban la diferencia entre 2 soles 40 centavos y los precios fijados para las ventas del estanco, con deducción de 10 centavos por quintal, es decir, 15 centavos de diferencia el primer semestre y 25 centavos en el segundo. Esta exportación estaba bajo vigilancia de la administración del estanco.

La legítima preocupación de Billinghurst era para con los establecimientos que no se expropiarían, pues si se les aplicaba el monto más alto (60 centavos) del rango del impuesto, simplemente quebrarían quedando a merced de los "capitalistas de Lima". Efectivamente, el 14 de diciembre de 1875 se decretó un impuesto de 60 centavos, que fue establecido en su artículo $1^{\circ}$.

Ley de expropiación: 28 de mayo de 1875 . Autorizaba esta ley solicitar un empréstito no superior a los 7 millones de libras esterlinas, donde cuatro millones eran para la compra de terrenos y establecimientos salitrales y los otros tres para concluir los trabajos de los ferrocarriles y para atender necesidades generales de la Nación. Pardo había, según Valentín Paniagua, tomado conciencia de la necesidad de vías de comunicación en un Perú de geografía amplia y difícil, antes de ser presidente, después de "haber experimentado el aislamiento en su estadía en Jauja", respaldando "decididamente al Congreso en su propósito de dictar una ley que autorizara la construcción de ferrocarriles" (Paniagua 2009:58).

No fue fácil conseguir esos recursos para comprar las salitreras; el Gobierno comisionó al señor Carlos Pividal, entregándole plenos poderes para que negociara en Europa el empréstito, pero fue en vano. Como señala una Memoria del Gobierno peruano al Congreso en 1878: "Tales resultados colocaron al Gobierno en una situación verdaderamente angustiosa, pues se hallaba ya en posesión de casi todos los establecimientos salitreros, vencidos unos y por vencer otros, los certificados salitreros provisionales otorgados ya, y en la imposibilidad de obtener un empréstito que debiera proporcionarle el medio de llenar sus compromisos" (Graña 1899:9). Sería un contrato con el Banco "La Providencia" el que salvaría al Gobierno de Pardo de esta situación.

Para llevar a la práctica el proceso de expropiación, al día siguiente de promulgada la ley (29 de mayo de 1875) se decretaron dos pliegos de datos sobre cada oficina salitrera. Se les pedía a los industriales que enviaran al Prefecto de Tarapacá, datos como: el número de estacas, la ley de caliche de las mismas, la distancia entre las calicheras y la planta de elaboración, las plantas y sistema de elaboración, la distancia al puerto de embarque, los caminos y las instalaciones (campamento), la facultad productiva, el stock de salitre, etc. No enviar estos datos se consideraba como una "negativa a tratar en arreglos con el Gobierno para la venta de los establecimientos salitreros". Sonaba, como lo denunciara Billinghurst, a una lógica ad baculum ${ }^{5}$.

¿Fue el estanco salitrero peruano tan beneficioso y tan mal comprendido? ¿Pretendía con él Manuel Pardo sólo acceder a una legítima contribución para el bien de la Nación que se encontraba en crisis económica?

Llama la atención que el principal argumento para expropiar las salitreras de Tarapacá, que es el que predomina en la historiografía peruana, es el que entrega Reyes Flores, a saber: "El salitre de Tarapacá era explotado por particulares, por el capital privado, en especial, chilenos y británicos para principios de la década de 1870, y el control que ejercía el Estado peruano era difuso" (Reyes Flores 1979:106). Agregando que: "La política salitrera seguida por las administraciones de Pardo y Prado se enfrentaba no sólo con los intereses chilenos, sino también con los poderosos capitalistas británicos. Es obvio que a los ingleses y por tanto a su Gobierno, no les va a agradar en lo absoluto la política peruana que tendía a beneficiar a los nacionales en detrimento de los extranjeros" (Reyes Flores 1979:108). Entonces, ¿dónde se ubican en ese cuadro los tarapaqueños-peruanos que eran poseedores hacia 1872 de más del $60 \%$ de la industria salitrera?, puesto que también fueron expropiados por la ley de 1875. ¿Cómo se explica el papel de la empresa británica Gibbs y Cía. en todo este proceso 
de expropiación que, supuestamente, beneficiaba a los "nacionales" versus los "extranjeros"?

La mirada de Alejandro Reyes Flores asocia a ingleses y chilenos en un conspirativo plan de despojo de territorios de Bolivia y Perú: "Los intereses económicos unieron a la clase dominante chilena y los capitalistas británicos. Ambos aspiraron a adueñarse del litoral boliviano, en primera instancia, y, seguidamente, del salitre de Tarapacá" (Reyes Flores 1979:108). ¿Cómo podría explicar este autor, entonces, la licitación peruana de la región salitrera boliviana de El Toco (región al sur del río Loa $21^{\circ}$ 20 ' 8"), antes de la Guerra del Pacífico? Una cita del prestigioso historiador peruano, Jorge Basadre, es muy clara al respecto: “...el presidente Pardo propuso a don Enrique Meiggs pagarle la deuda que el fisco le tenía si se presentaba como postor en el arrendamiento de El Toco; y Meiggs, a su vez, quiso tomar dichas salitreras y así obtener un arma con qué obligar a Pardo a continuar el plan de ferrocarriles o hacer el ajuste y liquidación de cuentas, bajo la amenaza de una lucha comercial" (Basadre 1969:151). Mover la frontera económica peruana hacia el sur del río Loa, a la región boliviana de El Toco, respondía a una lógica de control futuro del mercado del nitrato, cuando la industria salitrera chilena de Antofagasta y Taltal no eran todavía una competencia relevante (González 2010).

Manuel Pardo confió en un grupo asociado a la Banca limeña para llevar adelante su proyecto político de viabilidad, modernidad y progreso del Perú. Es así que tenemos al Banco La Providencia hacia 1879 controlando las compras y ventas de salitre de Tarapacá. Fueron los tarapaqueños, dueños de pequeñas plantas de lixiviación, los primeros en ser expropiados. La Asociación de los Bancos de Lima, aquellos relacionados con el civilismo, fue la que proporcionó "el capital que fue necesario para comprar al contado las pequeñas paradas $\mathrm{u}$ oficinas de sencilla explotación..." (Tagle Rodríguez 1918:141).

En síntesis, tanto la ley del estanco salitrero del 18 de enero de 1873 como la ley de nacionalización de la industria salitrera de 28 de marzo de 1875 , provocaron la ruina de muchos industriales, especialmente pequeños, perjudicó y benefició a algunas grandes compañías, donde la casa Gibbs y Cía. fue notoriamente recompensada. Salitreros tarapaqueños peruanos y chilenos estaban en la lista de los más afectados por esta política que pretendía arrebatar de las manos de quienes desde
1810 habían iniciado la exploración del desierto, la instalación de las primeras paradas salitreras y logrado su exportación, después de varios intentos frustrados. El salitre entonces no era competidor relevante del guano, que se había transformado en la principal exportación peruana y el respaldo de su endeudamiento. El guano estaba en manos fiscales hacia 1872 , pero estaba completamente comprometido con la Casa Dreyfus. Heraclio Bonilla nos dice

cuando Manuel Pardo asume en 1872 el control político del Estado no es sino para convertirse en el personaje impotente y entrampado de dos procesos opuestos pero convergentes: la más aguda crisis moderna del capitalismo internacional y la debacle de su propio grupo de sustento. El que estuvo en el centro de este doble movimiento fue Nicolás de Piérola, un hombre de 30 años, quien arrebata a los comerciantes nacionales la consignación del guano, es decir, la fuente principal de sus riquezas, para ponerla en manos de un oscuro comerciante francés: Auguste Dreyfus (Bonilla 1984:59).

Para lograr el éxito dicho proyecto, si era necesario, se podía pasar por sobre los intereses de grupos regionales e, incluso, ir más allá de las fronteras en busca de la supuesta oportunidad para el desarrollo.

\section{La Resistencia Tarapaqueña}

Billinghurst nos recuerda que, con excepción de don Jorge Smith, inglés, quienes iniciaron la explotación del salitre en Tarapacá fueron todos peruanos tarapaqueños. Tuvieron éstos una plena libertad de trabajo en la aventura de descubrir el caliche, elaborarlo y exportarlo, especialmente durante los gobiernos del tarapaqueño Ramón Castilla Marquesado. Un punto de inflexión fue cuando el químico chileno Pedro Gamboni logra aplicar vapor en la lixiviación del caliche, reemplazando de ese modo las antiguas paradas a fuego directo por el sistema a vapor o máquina. Los casos de Smith y Gamboni son dos ejemplos de empresarios que a partir de esfuerzo personal y persistencia lograron levantar sus industrias, como lo fue una gran mayoría de los empresarios salitreros de esa etapa fundacional. Fue la Banca chilena la que dio apoyo 
a muchos de estos emprendedores que estuvieron dispuestos a desafiar al desierto, enfrentados a una fácil ruina y a un siempre difícil éxito.

La libertad empresarial, que era por lo que luchaban los industriales tarapaqueños, generó un notorio auge de la producción y exportación de nitrato que es fácil de demostrar, pero dejemos a un testigo de época nos lo señale:

Grandes y halagüeñas eran las esperanzas que ofrecía esa naciente industria. El puerto de Iquique, cuya población en 1868 ascendía escasamente a 3.000 almas, alcanzó en 1871 a la considerable cifra de 11.700 . Las entradas de las aduanas de Iquique y Pisagua se habían triplicado, y la gran afluencia de inmigrantes por los vapores del sur, había convertido a Tarapacá en una nueva California, pero con riquezas más positivas, más reales, basadas en el cálculo y en la actividad fabril de sus laboriosos habitantes (Billinghurst 1875:12).

$\mathrm{Si}$ analizamos los apellidos de quienes construyeron máquinas que estaban operando entre 1870 y 1872, vemos sin duda alguna una mayoría de tarapaqueños como Loayza, Lafuente, Vernal y Castro, Marquesado, Calla, Hidalgo, Plaza, Arias, Granadino, Carpio, Tinaxas, Vilca. Entre 1874 y 1878, el periodo más difícil de la expropiación de la industria salitrera la capacidad productiva según nacionalidades era la siguiente (en quintales): Capital peruano 9.583,000; Capital chileno 3.120,000; Capital inglés 2.200,000; Capital alemán 1.250,000; Capital italiano 210,000 (Billinghurst 1889:18).

Sobre la reacción que tuvieron los tarapaqueños frente al estanco, se expresó en la dificultad que le pusieron al Gobierno de Pardo para definir las cuotas de producción de cada industrial, pues no le entregaron la información que requería. Fue entonces la propia Prefectura de Tarapacá la que elaboró el cuadro estadístico solicitado, por cierto, sin datos precisos, aún así organizó la Compañía Administradora del estanco de Salitre. Una vez constituida esta Compañía, se nombró a don Carlos H. Williams, como gerente de la Sucursal en Tarapacá, quien viajó desde Lima a Iquique acompañado de don Fabricio Cáceres, un personaje cercano del presidente Pardo ${ }^{6}$.

Revisando la correspondencia de Manuel Pardo en el Archivo General de la Nación, Perú, hemos podido comprobar que tempranamente el presidente tuvo antecedentes sobre la molestia que en Tarapacá generó la ley del estanco. Por razones de espacio, solamente incluimos dos extractos de cartas, de Pisagua y de Iquique, donde se le advierte al presidente Pardo sobre dicha molestia y acciones de rebeldía en la provincia al respecto.

Pisagua á 5 de Noviembre $1872^{7}$

\section{Excelentísimo Señor:}

Seguramente que V. E. tendrá conocimiento de los sucesos que van desenvolviéndose en esta provincia con motivo del proyecto de ley sobre el estanco del Salitre, y aunque nadie mejor que V. E. pueda apreciarlos, creo cumplir un deber poniendo en su conocimiento algunas pormenores.

El domingo habrá tenido lugar en Iquique una reunión que por mas que se denomine popular no es sino de salitreras y comerciantes, extranjeros en su mayor parte. $\mathrm{Su}$ objeto es, según se me há dicho, elevar una protesta al Gobierno ó al Congreso. Hoy, á la llegada del Vapor, debe saberse lo que há pasado.

Aunque considero solos á los promotores de la protesta, es indudable que están despedidas y serán capaces de todo. Así me hace presumir el descaro con que se habla aquí de una próxima insurrección, sin cuidarse (ilegible) de las autoridades..."

q. s. m. b.

Manuel J. de los Ríos (firma)

Iquique 11 (ilegible) $1872^{8}$

Mui Sr. mío y amigo.

Creo de mi deber, como buen amigo de $U^{d}$, el manifestarle el estado en que se encuentra la opinión en estos lugares.

Desde aier he notado que todos reciben mui mal el proyecto de ley sobre estanco de salitre. En Tacna crece mas esa mala impresión, y en este puerto es aun mayor el sigilo y resistencia.

He encontrado aquí impreso un papelucho que lo habia $U^{a}$ escrito ya.

Tanto en Arica como en Tacna y aquí, he hablado y hablo, siempre que la oportunidad me lo permite, en el sentido que $U^{d}$ 
me manifestó: Les he hecho notar los inconvenientes de la aglomeración de nuevas empresas: las dificultades que esto trae a la $H^{d a}$ Nacional y a la misma industria; y lo conveniente que es buscar un medio que, nivelando los intereses fiscales con

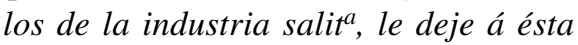
un porvenir, que siempre será seguro y permitirá su desarrollo natural; y le haga reportar é aquel mas renta (...)

(...)En Arica me han preguntado si sabía que el Presidente ha ofrecido la Iglesia de (ilegible) para ese puerto, y con este motivo me permito decirle que sería un bien positivo el que haría á ese desdichado pueblo que carece de todo y que (controla) el alma. Le agradecerán el regalo y será este un motivo para atenuar el calor que existe sobre el ferrocarril a la frontera y sobre salitre (...)

Me reitero de $U^{d}$ muy afectísimo $A g^{s} y$

(ilegible) S. M.

M. Moscoso Melgar (firma)

La presencia de estos viajeros-interventores generó malestar en Iquique, a tal punto que:

se hizo sentir en todos los círculos; hasta los hoteleros negaron a los emisarios del estanco hospedaje en sus establecimientos. Mr. William y el señor Cáceres fueron a Iquique sin blanca, que no tuvieron ni el dinero suficiente para regresar a Lima, viéndose obligados a solicitar a Mr Tate, gerente de la sucursal del Banco Nacional del Perú, dos mil soles en calidad de préstamo, que les fueron negados por dicho gerente y lo cual le valió más adelante su destitución (Billinghurst 1875:33).

Los tarapaqueños de esa forma demostraron su descontento con el Gobierno y midieron su poder.

El Gobierno ante esta situación, decretó 15 centavos por derechos de exportación a cada quintal de salitre, recaudado por la Compañía del estanco, privada, y que recibiría 3 centavos por comisión. Nos dice Billinghurst que bajo estas nuevas condiciones regresó Mr. Williams pero acompañado, esta vez, de "cincuenta Húsares que le guardaban las espaldas; el más concluyente de los argumentos de la legalidad de las medidas del Gobierno" (Billinghurst 1875:34).

Cuando los tarapaqueños viajaron a Lima vivieron la otra cara de la moneda. En su intento de llegar a un acuerdo sobre la base de lo que consideraban no sólo justo sino de sentido común, como era continuar con la libertad con la que habían trabajado hasta entonces y les había permitido ganar la batalla de los fertilizantes. Estaban, además, dispuestos a pagar un impuesto a la exportación de salitre que estuviera en un rango razonable a los costos de producción.

Pedro Dávalos y Lissón cuenta una interesante anécdota sobre el intento tarapaqueño de revertir las decisiones de Manuel Pardo respecto de la industria del salitre. "Una comisión de salitreros que presidió don Juan Gildemeister y de la que fue secretario Guillermo Billinghurst, tuvo varias conferencias en Chorrillos en el rancho de Tenderini, donde el presidente pasó el verano de 1874". El intercambio de frases más significativas lo resume Dávalos y Lissón del siguiente modo: "El estanco y después el monopolio nos ha arruinado -dijéronle-, Tarapacá comercialmente era nuestro. Nuestros capitales y nuestros brazos lo ha formado, y cuando comenzábamos a ver los frutos de nuestra empresa, se nos arroja y se nos arruina". Pardo les contestó: "Yo no he gobernado para ustedes ni para hacer la grandeza de Chile, sino para conseguir la ventura del Perú”. Dávalos y Lissón, con cierta ingenuidad, concluye que los tarapaqueños "carecieron de un buen abogado que hubiera hecho palpables sus buenas y justas razones. Se les creyó interesados únicamente en su negocio y no en el bien general" (Dávalos y Lissón 1928:36).

Guillermo Billinghurst, protagonista de ese encuentro, nos dice en 1875:

desde la inauguración del Gobierno de don Manuel Pardo, de aciaga memoria, surgirá la convicción, cada vez más profunda, de que la iniciativa del Gobierno en este asunto no tiene ni ha tenido otro móvil, que el marcado interés del círculo de mercaderes en cuyas manos se encuentran hoy la hacienda y los destinos del Perú (Billinghurst 1875:8).

Billinghurst no sería protagonista sólo de este encuentro con Pardo, sino que, siendo partidario 
de Piérola, se vio envuelto en la revuelta de este caudillo en contra del Gobierno entre octubre de 1874 y enero de 1875 , que se conoce como la expedición del Talismán. Jorge Basadre se pregunta ¿quiénes habilitaron económicamente a Piérola? Y entre los que identifica señala a "un grupo de industriales salitreros entre los que se destaca Guillermo Billinghurst" (Basadre 1969:407). No se puede establecer una relación directa entre los empresarios salitreros de Tarapacá en el intento golpista de Piérola, pero está comprobada la participación de Billinghurst. Además, en ese periodo se registraron revueltas en Tarapacá como las del coronel D.G. Albarracín ${ }^{9}$.

Ese sentimiento de ser víctimas de una expropiación indebida llevó a los tarapaqueños a boicotear el estanco salitrero en 1874. En la memoria del 30 de junio de 1874 del Director de Rentas, José M. Tirado, le comunicaba al Ministro de Hacienda: "esa ley (referida al estanco) no ha surtido sus efectos a pesar de las medidas adoptadas por el Gobierno; porque los productores no se habían presentado a la formación de los cuadros que determinaran las cuotas que debían producir, ni la Comisión que en efecto de ellos debía hacerlo, pudo reunirse no obstante los esfuerzos de la autoridad política de la provincia que se veía obligada a cumplir con las disposiciones dictadas por el Gobierno sobre el particular" (Flores Soria 2000:44).

El Ministro de Hacienda Juan Ignacio Elguera culpó a los productores de salitre en su Memoria presentada a la Legislatura Ordinaria de ese año, señalando que eran los grandes productores los responsables, al parecer no consideraba entre ellos a "la Casa Gibbs", la gran beneficiada del estanco salitrero. Lo relevante es que la protesta de los tarapaqueños fue recogida por la opinión pública peruana y el estanco fracasó de modo rotundo.

El fracaso del estanco salitrero obligó a Pardo a buscar otra alternativa para lograr el monopolio, y esta sería un impuesto de exportación en escala móvil, que iba de 15 a 60 centavos por quintal español de salitre, una tasa proporcional al precio del salitre y a las utilidades del productor.

El 8 de julio de 1876 el derecho de exportación de salitre fue nuevamente definido por Ley, al precio de un sol con veinticinco centavos. Y el 13 de julio se decretó la nueva tasación y el despueble de los estacamentos no explotados y abandonados. Todas estas medidas fueron firmadas por el Ministro de
Hacienda Sr. Juan Ignacio Elguera. Se preguntaba Billinghurst, "veremos al Gobierno de la República arruinando un floreciente departamento y sumiendo en la miseria a centenares de familias, ¿para conseguir qué?" (Billinghurst 1875:43). Y continuaba preguntándose, ¿se cree haber evitado así la cacareada competencia del salitre al guano? Defendía entonces los intereses de Tarapacá, en el Senado del Perú, el Gran Mariscal Gutiérrez de la Fuente, quien también era empresario salitrero.

Sin embargo, no todos perdieron con esta ley de expropiación de 1875 , como lo demuestra Manuel Ravest, con relación a la Casa Gibbs: "La Tarapacá Nitrate $\mathrm{C}^{\mathbf{o}}$, controlada por la filial peruana de "la Casa" y propietaria de las oficinas Carolina y Limeña, había perdido 484.524 soles entre 1873 y 1875 , en circunstancias que la inversión llegaba en ese último año a 1.274.524 soles. De manera que la posibilidad de abandonar un negocio en declinación vendiendo las oficinas al Estado y celebrando con su representante -el consorcio de Bancos Asociados- contratos de elaboración para operarlas era, de suyo, atractiva" (Ravest 2008a:67). Ravest continúa afirmando que para la Casa Gibbs, "el negocio fue considerado tan exitoso por la matriz londinense que escribió a su filial felicitándola y manifestándose dispuesta a apoyar el éxito de la nacionalización, a la que colaboraba financieramente desde el mes de mayo" (Ravest 2008a:67). Esta inequidad en beneficio de la Compañía inglesa se hizo con conocimiento del Gobierno del Perú.

Continúa Ravest (2008a:68):

"La Casa" obtuvo del consorcio bancario, en mayo de 1876, la exclusividad de la consignación del nitrato proveniente de la elaboración que él contrataba con los ex dueños de las oficinas, y el consorcio recibió de Gibbs un anticipo de £ 40.000. Los intereses del Estado, de los Bancos Asociados y de "la Casa" confluían armónicamente en dos puntos fundamentales: el volumen de producción y el de exportación del salitre.

En ese marco es que se puede entender la siguiente carta (fragmentos por razones de espacio) en la correspondencia del presidente Pardo en el Archivo General de la Nación en Lima, a saber: 
(Copia)

$$
\text { Lima, Diciembre } 2 \text { de } 1876^{10}
$$

Reservada

Señor Presidente de la Comisión de los Delegados de los Bancos Asociados

Pte.

Muy Señor Nstro.

La correspondencia que acabamos de recibir de nuestra casa de Londres por el último correo contiene datos tan importantes sobre el negociado de Salitres que nos permitimos dar á V. algunos extractos de ella con el objeto de que los estudie la comisión de Delegados que V. preside y adopte á la mayor brevedad las medidas que parecen necesarias para el buen éxito del negocio: Ntra casa de Londres después de hacer algunas reflexiones sobre las grandes dimensiones que ha tomado nuevamente la producción en Tarapacá, pasa á decirnos que hasta ahora ha almacenado el Salitre de los Bancos en diversos puntos del Reino Unido y así con grandes esfuerzos ha logrado sostener los precios en Europa, pero que no le convendría seguir haciendo toda clase de esfuerzos y sacrificios, si el Gobierno y los Bancos no toman en el acto medidas enérgicas para limitar la inmensa producción en la bolsa, único medio para establecer un monopolio y alzar el precio del Salitre en Europa (...)

(...)Hay dos medios para vencer la competencia de los productores libres: el primero es de vender el Salitre de los Bancos en Europa á un tipo que dejaría pérdida a cualquier otro, el segundo es alzar el derecho en la costa para que otros no puedan exportar sino vendan su producción al Gobierno.

Ambos medios tendrían probablemente el efecto inmediato de limitar la exportación, pero el primero causaría fuertes pérdidas á los Bancos sobre su existencia en Europa, y tendría solamente un efecto pasajero: luego que volviesen á subir los precios en Europa, volvería á la vida la producción libre, y estériles serian todos los esfuerzos y sacrificios para establecer un monopolio duradero así.

El segundo medio, el alzar los derechos de exportación, seria el único eficaz. Es evidente que $50^{d}$ por quintal no es suficiente para vencer la oposición de los productores libres, pues con las fluctuaciones en el cambio y los fletes, seguirán elaborando, y encontrarán compradores(...)

(...)Con el derecho actual de 50d nunca se logrará monopolizar el salitre ni en la Costa ni en Europa, y siempre quedará incompleta la negociación (...)

(...)No es la primera vez, Señor Presidente, que llamamos la atención de la Comisión de los Delegados que V. preside, á esta importante medida y hoy nos permitimos insistir en ella en vista de lo que nos dice por el último vapor Ntra casa de Londres, á saber:

"Ntras últimas cartas les han indicado ya que, si demostrásemos disposición á "vender en el día bajarán los precios en el acto, y habrá un grito general de sálvese quien pueda, el resultado seria desastroso "para los Bancos y los precios quedarán bajos por mucho tiempo. Ya hay rumores, tanto "aquí (Londres) como en el Continente de que el negocio no quedará en ntras manos. "Esto ya ha minado algo la confianza, y compradores que buscaban comprar Salitre "ahora poco, se han retirado del mercado para estar a la mira de lo que va á suceder. "Si los Bancos no pueden conseguir del Gobierno, que alze los derechos de "exportación en el acto, no vemos mas que un remedio para que se realice el monopolio, “y es el de bajar los precios en Europa á un tipo que haga imposible la competencia de "productores libres, _ pero esta baja causaría una gran perdida-al Gobierno y á los "Bancos y á penas parece creíble que se expondrían á sufrirla, cuando pueden evitarla "con la simple medida de alzar los derechos y establecer el monopolio, sin el cual fracasa "el negocio irremediablemente. "Pasamos a decir á U.U. que es ntra idea por ahora de no hacer nada que podría "deprimir los precios entre hoy dia $\left(1^{\circ}\right.$ de Noviembre) y el 31 de Diciembre.

"Esto dará tiempo al Gobierno y á los Bancos para tomar las medidas que "acabamos de indicar. "Pero si al fin de este año no ha mejorado la situación, no tendremos otro recurso que el "de principiar á vender, 
pues almacenar por meses y meses, sin que haya la seguridad "de que se establecerá el monopolio, causaría desde luego fuertes gastos, y no evitará "que al fin sufriesen los Bancos perdidas quizás aun mayores"(...) (...) que la Comisión de Delegados, que U. preside, recabe del Congreso, por conducto del Supremo Gobierno, la facultad de alzar los derechos de exportación y nos dice la casas de Londres de telegrafiarles a la mayor brevedad posible ${ }^{11}$ el resultado, pues si no se logra alzar los derechos, seria un error incalificable él de almacenar el Salitre de los Bancos, para que, en perjuicio del Estado, aprovechen otros de la actual alza ficticia de los precios en Europa.

Somos de U.; muy atentos y S.S.

(firmado) Gmo. Gibbs $C^{a}$ (firma)

Los beneficios de la Casa Gibbs estaban relacionados con la venta del salitre en el mercado europeo y con los intereses que generaban los empréstitos entregados al Gobierno de Pardo para la compra de las salitreras de Tarapacá. Como habíamos señalado, el Gobierno de Pardo transfirió la responsabilidad de administrar la expropiación a los Bancos peruanos, especialmente el Banco de la Providencia, cuyos accionistas eran consignatarios del guano, a través de la Compañía Nacional del Salitre. Los Bancos peruanos y el propio Gobierno de ese país sabían lo que significaba recibir por adelantado recursos financieros de grandes firmas europeas, ya lo habían experimentado con la Casa Dreyfus, lo que significó comprometer toda la producción del guano peruano. Se entiende por qué la Casa Gibbs estaba contenta con la nacionalización de las salitreras de Tarapacá y el Gobierno peruano también, pues este último veía en esa operación la salida a la crisis económica, por un lado, y asegurar el poder económico de su círculo de sustentación, por otro.

La Casa Gibbs había adquirido su influencia durante el Gobierno de Ramón Castilla Marquesado. Según José Arnaldo Márquez, en ese periodo, la casa Gibbs "se hallaba en sus negocios en una situación tan comprometida, que se llegó a resolver su liquidación" (Márquez 1888:5), pero, señala este autor, a través de gestiones con el Gobierno lograron quedar como consignatarios del guano para Europa "al ofrecer dinero en letras sobre Londres", a partir de entonces la influencia de la Casa Gibss "fundada en los suministros frecuentes de fondos al caprichoso Gobierno personal de Castilla, fue el punto de partida del poder ilimitado que un círculo de casas extranjeras ha alcanzado en el Perú" (Márquez 1888:7). Con Manuel Pardo esa influencia sería menor que en los Gobiernos de Castilla y Balta, pero aumentaría el poder de los bancos nacionales.

\section{Conclusiones}

Posiblemente una de las colisiones más interesantes entre un proyecto de desarrollo nacional y un proyecto de desarrollo regional, donde se enfrentaron grupos de empresarios capitalinos y grupos de empresarios locales en alianza con empresarios extranjeros, sea aquella que se efectuó en torno a la riqueza del nitrato de Tarapacá, durante el Gobierno de Manuel Pardo.

El triunfo de la economía salitrera tarapaqueña se debió, entre 1830 y 1876, a un emergente empresariado regional y extranjero, donde los componentes chileno e inglés fueron muy relevantes. El estanco y la expropiación no entregaron los frutos que de estas medidas esperaba el Gobierno de Manuel Pardo, posiblemente se debió en parte al boicot ejercido por los empresarios tarapaqueños, quienes resultaron derrotados definitivamente durante el Gobierno de Mariano Ignacio Prado. Con la Guerra del Pacífico, unos y otros perdieron, siendo el capital inglés el que al cabo de un par de décadas fue el principal triunfador. FranciscoValdés Vergara sostuvo que "lo que le faltó al Perú, en su régimen de estanco para que éste resultase fecundo, fue el tener derecho de soberanía sobre todo el territorio donde había salitre y eso lo tuvo Chile..." (Valdés Vergara 1913:360). Sin embargo, estudiando el caso chileno, a pesar de haber asegurado la soberanía de todo el territorio salitrero no se alcanzó el éxito de una política salitrera destinada a modernizar el país.

No sería la primera colisión que los empresarios mineros de Tarapacá tuvieron con el poder central, pues los mineros de la plata, los que explotaban las minas de Huantajaya y Santa Rosa, habían luchado a partir de 1776 por evitar los impuestos que debían pagar para el Virreinato peruano, por lo que en vez de llevar su plata al Corregimiento de Arica y abastecerse en Arequipa, optaron por el circuito de Carangas, que llevaba la plata a Oruro y Potosí (Gavira 2005:57). Entonces grandes mineros, como Basilio de la Fuente, tenían tanto poder que "se decía podía poner o quitar gobernadores" (Gavira 2005:38). Tampoco este movimiento de resistencia de los 
tarapaqueños sería el último que les enfrentaría con el Estado central, vendrán otros durante la soberanía chilena, como aquellas demandas por integración física con Oruro (Castro 2005), entre otras.
Agradecimientos: Se agradece a los evaluadores por sus sugerencias que contribuyeron al artículo. Este artículo es resultado del proyecto Fondecyt $\mathrm{N}^{\circ} 1100074$.

\section{Referencias Citadas}

Amayo, E. 1988. La Política Británica en la Guerra del Pacífico. Editorial Horizonte, Lima.

Basadre, J. 1969. Historia de la República del Perú. Volumen VII. Editorial Universitaria, Lima.

Bermúdez, O. 1963. Historia del Salitre desde sus Orígenes hasta la Guerra del Pacífico. Ediciones Universidad de Chile, Santiago.

Billinghurst, G. 1875. Rápida Ojeada sobre la Cuestión Salitre. Imprenta del Mercurio, Valparaíso.

- - - 1889. Los Capitales Salitreros de Tarapacá. Imprenta de El Progreso, Santiago.

Bonilla, H. 1974. Guano y Burguesía en el Perú. Instituto de Estudios Peruanos, Lima.

- - - 1980. Un Siglo a la Deriva. Ensayos sobre el Perú, Bolivia y la Guerra. Instituto de Estudios Peruanos, Lima.

- - - 1984. Guano y Burguesía en el Perú. Instituto de Estudios Peruanos, Lima.

Castro, L. 2005. Regionalismo y Desarrollo Regional: Debate Público, Proyectos Económicos y Actores Locales (Tarapacá 1880-1930). CEIP Ediciones, Viña del Mar.

Cotler, J. 2006. Clases, Estado y Nación en el Perú. Instituto de Estudios Peruanos, Lima.

Dávalos y Lissón, P. 1928. Leguía (1875-1899). Editorial Montaner y Simón, Barcelona.

De Lavalle, J.A. 1979. Mi Misión en Chile en 1879. Instituto de Estudios Histórico-Marítimos del Perú, Lima.

Donoso, C. 2003. Aguas de Iquique, desde Tiempos Precolombinos hasta 1912. Universidad Bolivariana, Colección Estudios Regionales, Santiago.

Flores Galindo, A. 1980. El militarismo y la dominación Británica. En Nueva Historia General del Perú, editado por C. Araníbar y H. Bonilla, pp. 107-122. Ediciones Mosca Azul, Lima.

Flores Soria, C. 2000. El civilismo y la cuestión del salitre, 18721876. Historia, Revista de Historia y Sociedad Año I, No 1 , Lima.

Gavira, M.C. 2005. Producción de plata en el mineral de San Agustín de Huantajaya (Chile), 1750-1804. Chungara Revista de Antropología Chilena 37:37-57.

González, S. 2006. El Toco y la Guerra del Pacífico: una hipótesis de trabajo. Hombre y Desierto una Perspectiva Cultural 13:7-25.

- - - 2010. El impacto de la política salitrera peruana en la región salitrera del Toco (1872-1878): un capítulo pendiente en el origen de la Guerra del Pacífico. En Chile y la Guerra del Pacífico, editado por C. Donoso Rojas y G. Serrano del Pozo, pp. 315-359. Universidad Andrés Bello, Centro de Estudios Bicentenario, Santiago.
Graña, D.W. 1899. Compañía Salitrera del Perú. Memorial presentado a los Excmos. Sres. Ministros Plenipotenciarios de España, Estados Unidos de Norte América e Italia y Encargado de Negocios de Gran Bretaña. Imprenta, Litografía y Encuadernación Barcelona, Santiago.

Mathew, W. 2009. La Firma Inglesa Gibbs y el Monopolio del Guano en el Perú. Instituto de Estudios Peruanos, Lima.

Mc Evoy, C. 1994. Un Proyecto Nacional en el Siglo XIX. Manuel Pardo y su Visión del Perú. Pontificia Universidad Católica del Perú, Lima.

- - - 1997. La Utopía Republicana. Ideales y Realidades en la Formación de la Cultura Política Peruana (1871-1919). Pontificia Universidad Católica del Perú. Fondo Editorial, Lima.

Mücke, U. 2004. Elecciones y participación política en el Perú del siglo XIX: la campaña presidencial de 1871-72. Investigaciones Sociales VIII:133-166, Lima.

Paniagua, V. 2009. Manuel Pardo y el Partido Civil. Apogeo y Crisis del Primer Partido Político en el Perú. Fondo Editorial del Congreso del Perú, Lima.

Pereda, R. 1982. Historia de las Luchas Sociales del Movimiento Obrero en el Perú Republicano 1858-1917. EDIMSSA, Lima.

Raimondi, A. 2003. Informes y Polémicas sobre el Guano y el Salitre (Perú 1854-1877). Universidad Mayor de San Marcos, Lima.

Ravest, M. 2008a. La Casa Gibbs y el monopolio salitrero peruano: 1876-1878. Historia 41:63-77.

- - - 2008b. La saga de las calicheras del Toco 1876-1924. Boletín de la Academia Chilena de la Historia LXXIV:191-245.

Reyes Flores, A. 1979. Relaciones internacionales en el Pacífico Sur, ensayo de interpretación: 1873-1879. En La Guerra del Pacífico, editado por W. Reátegui Cháves V. I, pp. 39-96. Universidad Mayor de San Marcos, Dirección Universitaria de Biblioteca y Publicaciones, Lima.

Semper, E. y E. Michels 1908. La Industria del Salitre en Chile. Imprenta, Litografía y Encuadernación Barcelona, Santiago.

Tagle Rodríguez, E. 1918. Legislación de Minas. Tomo Segundo. Imprenta Chile, Santiago.

Valdés Vergara, F. 1913. Problemas Económicos de Chile. Imprenta y Litografía Universo, Valparaíso.

\section{Archivos consultados}

Archivo de Intendencia de Tarapacá, Chile (AIT) Archivo Histórico Nacional. Fondo Prefectura de Tarapacá (AHN). Archivo General de la Nación, Perú (AGN) Periódico La Libertad Electoral, Santiago, 1888. 


\section{Notas}

1 La idea de patria como propaganda política había surgido en las elecciones de 1871, como lo indica Mücke (2004:149) "la retórica de las cartas, artículos de periódico y volantes continuamente aludía al bien de la patria, enfatizando el aspecto nacional de las elecciones presidenciales".

2 Los clubes, donde se expresaban los "independientes", Valentín Paniagua (2009:79) señala que era un "eufemismo detrás del cual se esbozaban los intentos de organización político-partidista", donde Pardo tendría un papel relevante en la organización de los partidos políticos.

3 Pardo se hizo asesorar por el sabio italiano Antonio Raimondi respecto del guano y del salitre (Raimondi 2003).

4 Para una revisión de las leyes y decretos leyes del Gobierno peruano sobre el salitre en el periodo estudiado ver los anexos páginas 129-151 de la Memoria del delegado fiscal de salitreras J.F. Campaña del año 1900.

5 El proceso de entrega de certificados al portador del Gobierno peruano a los salitreros antes de la Guerra del Pacífico fue notoriamente confuso, a tal punto que el Gobierno chileno en 1886 le solicitó a Pedro Nolasco Gandarillas, quien fuera ministro de Hacienda del presidente Balmaceda, que realizara una cuenta detallada de los certificados emitidos por Perú, informe que entregó un año después sin lograr completamente su objetivo.

6 No sería la primera vez que un súbdito inglés sería escogido por el Gobierno peruano para hacer un catastro de la capacidad productiva de cada oficina salitrera de Tarapacá, el siguiente sería ni más ni menos que Mr Robert Harvey, quien en calidad de Fiscal de las Salitreras tuvo la información privilegiada que benefició a John Thomas North (y a él mismo) para la compra de las mejores estacas salitreras cuando la incertidumbre se apoderó de los pequeños y medianos salitreros de Tarapacá, en el marco de la Guerra del Pacífico, quienes vendieron sus certificados en una fracción de su valor.

7 Archivo General de la Nación. Colección Cartas a Manuel Pardo. D2. 36-2479, ff. 12-14.

8 Archivo General de la Nación. Colección Cartas a Manuel Pardo. D2. 28-1904, ff. 1-5.

9 Archivo Histórico Nacional, Fondo Prefectura de Tarapacá, documento 17, p. 285.

10 Archivo General de la Nación. Colección Cartas a Manuel Pardo. D2. 51-3385, ff. 1-4.

11 Los subrayados corresponden a la carta original. 